\title{
GENETIC PARAMETERS FOR DIRECT AND MATERNAL EFFECTS ON DIFFERENT GROWTH RATES IN BARKI LAMBS
}

\author{
Gad, S. M. A. \\ Animal and Poultry Breeding Dept., Desert Research Centre, El Matareya, Cairo, Egypt \\ Email: soliman_gad@yahoo.com
}

\section{SUMMARY}

To investigate direct and maternal effects on growth rates taken at various intervals in Barki sheep, body weight data were obtained from the Barki sheep flock from 1994 to 2001. Records of 1169 lambs, progenies of 690 ewes and 83 sires, were used. Heritability and correlation estimates were estimated by DFREML program. Six different animal models were fitted by including or excluding maternal effects while regarding sex, year of birth and age of dam as fixed effects and animal, sire and dam as random effects. Akaike information criterion (AIC) was used to determine the most appropriate model for the studied traits. Average growth rate during preweaning stage was higher than that of post-weaning ones. Based on AIC, Model two is the most appropriate model for $G R_{b-w}$ and $G R_{b-6 m}$. Whereas Model one is the best model for $G R_{w-6 m}, G R_{b-9 m}, G R_{w-9 m}$ and $G R_{6 m-9 m} l o w$ estimates of $h_{d}^{2}$ indicate that low genetic improvement is expected for growth rates in Barki sheep. However, selection for $G R_{b-w}$ would be more effective than other studied growth rates. The relatively higher and positive additive genetic correlations between $G R_{b-w}$ and other post-weaning growth traits might reveal that growth rate from birth to weaning is a suitable selection criterion to improve growth performance in Barki sheep.

\section{Keywords: Barki sheep, animal model, heritability, growth rate}

\section{INTRODUCTION}

In mammalian species, growth traits are not only influenced by the genes of the individual for growth and the environment under which it is raised, but also by the maternal genetic and environment provided by the dam (Ekiz, 2005). In young animals, the milk supply of their dam and the maternal care, provide contribution to their growth (Bradford, 1972; Lewis and Beatson, 1999 and Ekiz, 2005). The genotype of the dam affects the phenotype of the young through a sample of half her direct additive genes for growth in addition to her maternal effects on growth (Meyer, 1992). The efficiency of selection in a maternally influenced trait can sometimes be reduced when direct heritability considered alone as a result of a negative correlation between direct and maternal influences, which in turn results in a lower total heritability (Snyman et al., 1995). While some literatures indicated negative associations between direct and maternal genetic effects for growth traits (Yazdi et al., 1997, Van Wyk et al., 2003 and Ekiz 2005), other reports showed positive relationships (Maria et al., 1993; Matika, 2003 and El-Wakil and $\mathrm{Gad}$, 2014). There are wide discrepancies in the literatures regarding the intervals during which the growth rate is usually measured. Improving growth performance through breeding programs is an important way to increase meat output in lamb production systems. Selection for growth traits is complicated since it is determined not only by the animal's own additive genetic merit but also by maternal effects and ignoring the later would result in overestimation of direct heritability and hence a biased predicted responses to selection (GhafouriKesbi and Eskandarinasab, 2008 and Barazandeh et al., 2011). Therefore, both direct and maternal effects have to be considered in selection procedures (Ghafouri-Kesbi and Eskandarinasab, 2008). The objectives of the present study were, first, to determine the most appropriate model for the data set used and, secondly, to investigate the importance of maternal genetic and environmental effects on growth rates taken at various intervals in Egyptian Barki lambs.

\section{MATERIALS AND METHODS}

Data were obtained from the records of the Barki sheep flock raised at Maryout Research Station, (35 $\mathrm{km}$ west of Alexandria) belongs to the Desert Research Center through the period from 1994 to 2001. At birth, lambs were ear-tagged and kept with their mother's to suckle and weighed within 24 hours after birth and weaned at four months of age. Body weights were recorded at birth and biweekly intervals until weaning and monthly intervals till the animals were culled from the flock. Ewes were often first mated at approximately 16 months of age. Detailed feeding and flock management was described elsewhere (El-Wakil et al., 2009). Body weight records consist of 1169 lambs, progenies of 690 ewes and 83 sires, were used, growth rate, b, w, 6m, and $9 \mathrm{~m}$ : birth, weaning, at six month, at nine month, respectively.

\section{Statistical analysis}

Estimates of (co)variance components and log likelihood values for growth rates at different intervals were obtained using Derivative-Free Restricted Maximum Likelihood (DFREML) procedures (Boldman et al., 1995). GLM procedure 
(SAS, 2004) was performed on a model including fixed effects of sex, year and age of dam. All these fixed effects were significant for all traits studied and were included in the models. Also, the model included the animal, sire and dam as random effects Six different animal models were fitted for each trait, by ignoring or including maternal genetic effect, covariance between direct-maternal effects and maternal permanent environmental effect as follows:

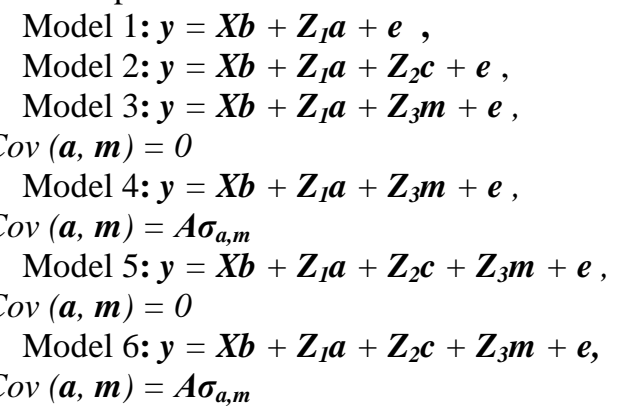

Where $\boldsymbol{y}$ is the vector of observations, $\boldsymbol{b}$ is the vector of fixed effects, $\boldsymbol{a}, \boldsymbol{m}, \boldsymbol{c}$ and $\boldsymbol{e}$ are the vectors of direct additive genetic effect, maternal genetic effect, maternal permanent environmental effect and the residual effect, respectively. $\boldsymbol{X}, \boldsymbol{Z}_{1}, \boldsymbol{Z}_{2}$ and $\boldsymbol{Z}_{3}$ are incidence matrices relating individual records to $\boldsymbol{b}, \boldsymbol{a}$, $\boldsymbol{c}$ and $\boldsymbol{m}$, respectively. The (co)variance structure for the model was:

$$
\begin{array}{r}
V(a)=A \sigma_{a}^{2}, V(\boldsymbol{m})=A \sigma_{m}^{2}, V(\boldsymbol{c})= \\
\operatorname{In}{\sigma_{c}^{2}}_{c}, V(\boldsymbol{e})=I_{e} \boldsymbol{\sigma}_{e}^{2} \text { and } \operatorname{Cov}(\boldsymbol{a}, \boldsymbol{m})=\boldsymbol{A} \boldsymbol{\sigma}_{a, m}
\end{array}
$$

where $\boldsymbol{I}_{n}$ and $\boldsymbol{I}_{\boldsymbol{e}}$ are identity matrices of order equal to the number of dams and number of records, respectively. $\sigma_{a}^{2}, \sigma_{m}^{2}, \sigma_{c}^{2}$ and $\sigma_{e}^{2}$ are direct additive genetic variance, maternal genetic variance, maternal permanent environmental variance, and residual variance, respectively, and $\sigma_{a, m}$ is direct-maternal genetic covariance. Analysis of animal models was used to generate variance components and estimate direct $\left(\mathrm{h}_{\mathrm{d}}^{2}\right)$ and maternal heritabilities $\left(\mathrm{m}^{2}\right)$ and direct genetic, maternal and phenotypic correlations. The bivariate animal models which included the same fixed effects as univariate models were used to estimate (co) variances between each pair of traits. The models applied in two trait analyses were those fitted for each of the underlying traits in the single trait analyses. DFREML program of Boldman et al. (1995) was also used to estimate genetic parameters with a REML algorithm. A variance of $10^{-9}$ of simplex function values was chosen as the convergence criterion which gives a good accuracy of estimation. Traditionally log-likelihood ratio tests (LRT) were used to determine the most appropriate model by comparing the differences between loglikelihoods $(-2 \log \mathrm{L})$ to a critical value from a chisquare distribution. Using LRT, only models that differ by at least one parameter are comparable, i.e., comparison of Model 2 with Model 3 is not feasible by LRT because both models include the same number of parameters. For this reason, the Akaike information criterion (AIC) of Akaike (1973) was computed to rank the models. Let $\mathrm{p}$ denote the number of random (co) variance parameters to be estimated and $-2 \log \mathrm{L}$ is the maximum likelihood, then the Akaike information criterion is defined as: $\mathrm{AIC}=-2 \log \mathrm{L}+2 \mathrm{p}$. The model yielding the smallest AIC fits the data best.

\section{RESULTS AND DISCUSSION}

Different growth rates are presented for various growth phases in table (1). The average growth rate during pre-weaning period was higher than that of post-weaning ones. Even though the growth rate associated with birth weight appeared to be consistently higher than the corresponding ones started from weaning while the least growth rate was recorded for GR $6 \mathrm{~m}-9 \mathrm{~m}$. That difference might be attributed to changes in feeding stuff after the suckling period.

AIC values for different models are presented in table (2). Based on AIC, Model two is the most appropriate model for $\mathrm{GR}_{\mathrm{b}-\mathrm{w}}$ and $\mathrm{GR}_{\mathrm{b}-6 \mathrm{~m}}$ in which maternal genetic effect was ignored, whereas Model one is the best model describing the data of other studied growth rates. For $\mathrm{GR}_{\mathrm{w}-6 \mathrm{~m}}, \mathrm{GR}_{\mathrm{b}-9 \mathrm{~m}}, \mathrm{GR}_{\mathrm{w}-9 \mathrm{~m}}$ and GR $6 \mathrm{~m}-9 \mathrm{~m}$, the model including only direct additive effect (Model 1) was sufficient to explain the variation in the data. It is notable that data structure has a great impact on the accuracy of maternal effects estimation. Maniatis and Pollott (2002) indicated that a large data set and several well-linked generations of records and many relationship between relatives related to the mother were needed to accurately separated maternal genetic components and maternal permanent environmental effects from combined and direct effects.

Table (1). Estimates of growth rates (GR) at various intervals in Barki lambs

\begin{tabular}{lcc}
\hline GR & No & Mean \pm SE \\
\hline $\mathrm{GR}_{\mathrm{b}-\mathrm{w}}$ & 1169 & $130.90 \pm 0.96$ \\
$\mathrm{GR}_{\mathrm{b}-6 \mathrm{~m}}$ & 978 & $111.20 \pm 0.74$ \\
$\mathrm{GR}_{\mathrm{w}-6 \mathrm{~m}}$ & 978 & $87.24 \pm 0.71$ \\
$\mathrm{GR}_{\mathrm{b}-9 \mathrm{~m}}$ & 791 & $95.61 \pm 0.67$ \\
$\mathrm{GR}_{\mathrm{w}-9 \mathrm{~m}}$ & 791 & $74.42 \pm 0.72$ \\
$\mathrm{GR}_{6 \mathrm{~m}-9 \mathrm{~m}}$ & 791 & $60.10 \pm 0.90$
\end{tabular}

$\mathrm{GR}=$ growth rate, $\mathrm{b}, \mathrm{w}, 6 \mathrm{~m}$, and $9 \mathrm{~m}$ : birth, weaning, at 6 month, at 9 month, respectively.

Model one which ignored maternal effects resulted in generally higher estimates of $\mathrm{h}_{\mathrm{d}}^{2}$ than did the other models (Table 2). Estimates of $h^{2}{ }_{d}$ ranged from 0.08 to 0.18 as indicated from table (2). Fitting maternal permanent environmental variance $\left(c^{2}\right)$ in Model two generally reduced the estimates of $\mathrm{h}_{\mathrm{d}}^{2}$ compared to Model 1, while inclusion of maternal genetic effects (Models 3-6) showed further reduction in $\mathrm{h}^{2}{ }_{\mathrm{d}}$ for which there is negligible differences in $\mathrm{h}^{2}{ }_{\mathrm{d}}$ of the other models within each trait. 
Table 2. Direct $\left(h^{2}+\mathrm{SE}\right)$ and maternal heritability $\left(\mathrm{m}^{2} \pm \mathrm{SE}\right)$ as well as direct $\left(\mathrm{e}^{2} \pm \mathrm{SE}\right)$, maternal permanent environmental variances $\left(c^{2} \pm \mathrm{SE}\right)$ and $\mathrm{AIC}$ values for average growth rates at various intervals obtained from various models in Barki lambs

\begin{tabular}{|c|c|c|c|c|c|c|}
\hline GRlintervals & Models & $\mathbf{h}_{\mathrm{d}}^{2}$ & $\mathbf{m}^{2}$ & $c^{2}$ & $\mathbf{e}^{2}$ & AIC \\
\hline \multirow[t]{6}{*}{$\mathrm{GR}_{\mathrm{b}-\mathrm{w}}$} & 1 & $0.17 \pm 0.06$ & - & - & $0.83 \pm 0.06$ & 8993.89 \\
\hline & 2 & $0.14 \pm 0.06$ & - & $0.06 \pm 0.04$ & $0.80 \pm 0.06$ & 8991.01 \\
\hline & 3 & $0.14 \pm 0.06$ & $0.06 \pm 0.04$ & - & $0.80 \pm 0.06$ & 8993.29 \\
\hline & 4 & $0.13 \pm 0.06$ & $0.02 \pm 0.14$ & - & $0.80 \pm 0.06$ & 8992.90 \\
\hline & 5 & $0.14 \pm 0.06$ & 0.00 & $0.06 \pm 0.2$ & $0.80 \pm 0.06$ & 8995.29 \\
\hline & 6 & $0.13 \pm 0.06$ & $0.03 \pm 0.27$ & 0.00 & 0.770 .06 & 8995.49 \\
\hline \multirow{6}{*}{$\mathrm{GR}_{\mathrm{b}-6 \mathrm{~m}}$} & 1 & $0.18 \pm 0.07$ & - & - & $0.82 \pm 0.07$ & 6857.74 \\
\hline & 2 & $\mathbf{0 . 1 2} \pm 0.07$ & - & $0.10 \pm 0.05$ & $0.77 \pm 0.07$ & 6856.96 \\
\hline & 3 & $0.12 \pm 0.07$ & $0.11 \pm 0.06$ & - & $0.78 \pm 0.07$ & 6858.70 \\
\hline & 4 & $0.11 \pm 0.07$ & $0.04 \pm 0.17$ & - & $0.78 \pm 0.07$ & 6858.28 \\
\hline & 5 & $0.12 \pm 0.07$ & $0.11 \pm 0.23$ & 0.0 & $0.78 \pm 0.07$ & 6860.70 \\
\hline & 6 & $0.12 \pm 0.07$ & 0.00 & $0.08 \pm 0.23$ & $0.78 \pm 0.07$ & 6860.50 \\
\hline \multirow[t]{6}{*}{$\mathrm{GR}_{\mathrm{w}-6 \mathrm{~m}}$} & I & $0.14 \pm 0.07$ & - & - & $0.86 \pm 0.07$ & 6704.67 \\
\hline & 2 & $0.14 \pm 0.07$ & - & $0.19 \pm 0.05$ & $0.67 \pm 0.07$ & 6706.67 \\
\hline & 3 & $0.14 \pm 0.07$ & 0.00 & - & $0.86 \pm 0.07$ & 6708.67 \\
\hline & 4 & $0.13 \pm 0.07$ & 0.00 & - & $0.85 \pm 0.07$ & 6708.59 \\
\hline & 5 & $0.14 \pm 0.07$ & 0.00 & 0.00 & $0.86 \pm 0.07$ & 6710.67 \\
\hline & 6 & $0.14 \pm 0.07$ & 0.00 & $0.02 \pm 0.29$ & $0.79 \pm 0.07$ & 6710.82 \\
\hline \multirow[t]{6}{*}{$\mathrm{GR}_{\mathrm{b}-9 \mathrm{~m}}$} & I & $0.16 \pm 0.08$ & - & - & $0.84 \pm 0.08$ & 5179.48 \\
\hline & 2 & $0.11 \pm 0.07$ & - & $0.10 \pm 0.06$ & $0.79 \pm 0.08$ & 5181.47 \\
\hline & 3 & $0.11 \pm 0.07$ & $0.10 \pm 0.06$ & - & $0.79 \pm 0.08$ & 5181.49 \\
\hline & 4 & $0.11 \pm 0.07$ & $0.04 \pm 0.23$ & - & $0.79 \pm 0.08$ & 5181.22 \\
\hline & 5 & $0.11 \pm 0.07$ & 0.00 & $0.10 \pm 0.35$ & $0.78 \pm 0.08$ & 5183.04 \\
\hline & 6 & $0.11 \pm 0.08$ & 0.00 & $0.11 \pm 0.35$ & $0.79 \pm 0.08$ & 5183.07 \\
\hline \multirow[t]{6}{*}{$\mathrm{GR}_{\mathrm{w}-9 \mathrm{~m}}$} & I & $0.15 \pm 0.08$ & - & - & $0.85 \pm 0.08$ & 5175.91 \\
\hline & 2 & $0.14 \pm 008$ & - & $0.03 \pm 0.06$ & $0.84 \pm 0.08$ & 5177.77 \\
\hline & 3 & $0.14 \pm 0.08$ & $0.01 \pm 0.06$ & - & $0.84 \pm 0.08$ & 5177.86 \\
\hline & 4 & $0.14 \pm 0.08$ & $0.03 \pm 0.25$ & - & $0.76 \pm 0.08$ & 5181.79 \\
\hline & 5 & $0.14 \pm 0.08$ & 0.00 & $0.03 \pm 0.43$ & $0.84 \pm 0.08$ & 5181.27 \\
\hline & 6 & $0.14 \pm 0.08$ & $0.04 \pm 0.58$ & 0.00 & $0.75 \pm 0.08$ & 5184.36 \\
\hline \multirow[t]{6}{*}{$\mathrm{GR}_{6 \mathrm{~m}-9 \mathrm{~m}}$} & I & $0.09 \pm 0.07$ & - & - & $0.91 \pm 0.07$ & 5566.32 \\
\hline & 2 & $0.08 \pm 0.07$ & - & $0.04 \pm 0.06$ & $0.88 \pm 0.07$ & 5568.05 \\
\hline & 3 & $0.08 \pm 0.07$ & $0.03 \pm 0.06$ & - & $0.88 \pm 0.08$ & 5570.05 \\
\hline & 4 & $0.12 \pm 0.08$ & $0.21 \pm 0.27$ & - & $0.83 \pm 0.09$ & 5569.25 \\
\hline & 5 & $0.08 \pm 0.07$ & $0.04 \pm 0.52$ & 0.00 & $0.88 \pm .0 .08$ & 5572.05 \\
\hline & 6 & $0.13 \pm 0.08$ & $0.06 \pm 0.60$ & 0.00 & $0.71 \pm 0.08$ & 5577.35 \\
\hline
\end{tabular}

$\mathrm{GR}=$ growth rate, $\mathrm{b}, \mathrm{w}, 6 \mathrm{~m}, 9 \mathrm{~m}$ : birth, weaning, at 6 month, at 9 month, respectively. The ratio of direct $\left(\mathrm{e}^{2}=\right.$ $\left.\sigma_{e}^{2} / \sigma_{p}^{2}\right)$ and maternal $\left(c^{2}=\sigma_{c}^{2} / \sigma_{p}^{2}\right)$ permanent environmental variances to the phenotypic variance $\left(\sigma_{p}^{2}\right)$, $\mathrm{AIC}=$ Akaike information criterion (best models are in bold). $\pm \mathrm{SE}=$ standard errors.

The present estimate of $\mathrm{h}_{\mathrm{d}}^{2}$ for $\mathrm{GR}_{\mathrm{b}-\mathrm{w}}$ was found to be within the range of 0.13 to 0.26 for the corresponding values estimated from different animal models in the same Barki sheep flock as reported by El-Wakil, and Gad (2014). Moreover, the same authors found that estimates of $h^{2}$ for the growth rate from weaning to yearling stage to be ranged from 0.08 to 0.10 . Direct additive genetic effects for average growth rates obtained from the appropriate models appeared to be low to moderate values which indicate that low genetic improvement is expected for growth traits in Barki sheep. However, selection for $\mathrm{GR}_{\mathrm{b}-\mathrm{w}}$ and $\mathrm{GR}_{\mathrm{b}-6 \mathrm{~m}}$ would be more effective compared with other studied growth rates.

Table (2) showed that estimates of $\mathrm{m}^{2}$ had slight differences within each trait (Models 3-6) and ranged from 0.02 to 0.21 . Estimates of $\mathrm{m}^{2}$ for average growth rates were slightly low in the models without directmaternal covariance, whereas the opposite trend occurred for those models with the negative covariance between direct and maternal genetic effect. 
In Barki sheep of the same flock, El-Wakil, and Gad (2014) used six animal model reported that estimates of $\mathrm{m}^{2}$ ranged from 0.10 to 0.17 for GR from birth to weaning and from 0.01 to 0.07 for growth rate from weaning to yearling. These results indicated poor maternal genetic variability compared with the direct genetic one which might reveal that selection for growth rates should be based on direct heritability rather than maternal ones in Barki sheep.

Estimates of maternal permanent environmental effects $\left(c^{2}\right)$ seems to be less than direct environmental effects $\left(\mathrm{e}^{2}\right)$ which also indicate the importance of direct environmental effects compared with maternal permanent ones in controlling growth rates in Barki sheep (Table 2). In Barki sheep, El-Wakil, and Gad (2014) found that estimates of $\mathrm{c}^{2}$ ranged from 0.05 to 0.14 for GR from birth to weaning and from 0.00 to 0.14 for growth rate from weaning to yearling. Maternal permanent environmental effects were generally low while the highest estimate obtained was 0.19 for $\mathrm{GR}_{\mathrm{w}-6 \mathrm{~m}}$. These effects may be due to the effects of uterine environment and multiple births on milk production of ewes, level of nutrition at late gestation and maternal behavior (Maria et al., 1993 and Snyman et al., 1995).

Correlations coefficients among studied growth rates are showed in table (3). The additive genetic correlations of $\mathrm{GR}_{\mathrm{b}-\mathrm{w}}$ and $\mathrm{GR}_{\mathrm{w}-6 \mathrm{~m}}$ with other studied growth rates at different stages were generally higher than the corresponding maternal genetic ones. Whereas those additive genetic correlations of $\mathrm{GR}_{\mathrm{b}-6 \mathrm{~m}}$ with other studied growth rates were generally less than the respective maternal genetic correlations. Additive genetic correlations among studied growth rates were positive and ranged from 0.19 to 0.89 . The phenotypic correlations between studied growths rates measured at different intervals were lower than the corresponding direct additive genetic ones which agreed in general with findings obtained elsewhere (Pollott et al., 1998; Mousa et al., 1999; GhafouriKesbi and Baneh, 2012 and El-Wakil and Gad, 2014). The relatively higher and positive additive genetic correlations between $\mathrm{GR}_{\mathrm{b}-\mathrm{w}}$ and other postweaning growth traits, makes this trait to be a suitable selection criterion to improve growth performance of the Barki sheep.

\section{CONCLUSION}

Our results indicate the importance of direct genetic and environmental effects rather than maternal genetic and permanent environmental effects in controlling growth rates at various intervals in Barki sheep. Therefore, selection based on direct genetic effects would be more effective and using $\mathrm{GR}_{\mathrm{b}-\mathrm{w}}$ would be better than any other form of growth rates in this flock. The relatively higher and positive additive genetic correlations between $\mathrm{GR}_{\mathrm{b}-\mathrm{w}}$ and other post-weaning growth traits might reveal that growth rate from birth to weaning is a suitable selection criterion to improve growth performance in Barki sheep.

\section{ACKNOWLEDGEMENT}

Prof. Hassanein El Gabbas is greatly acknowledged for his valuable comments and reading the manuscript.

Table 3. Correlations coefficients between studied growth rates estimated from bi-variate analysis

\begin{tabular}{lllcc}
\hline Trait 1 & \multicolumn{1}{c}{ Trait 2 } & $\mathbf{r}_{\mathbf{a}}$ & $\mathbf{r}_{\mathbf{m}}$ & $\mathbf{r}_{\mathbf{p}}$ \\
\hline $\mathrm{GR}_{\mathrm{b}-\mathrm{w}}$ & $\mathrm{GR}_{\mathrm{b}-6 \mathrm{~m}}$ & 0.89 & 0.69 & 0.46 \\
$\mathrm{GR}_{\mathrm{b}-\mathrm{w}}$ & $\mathrm{GR}_{\mathrm{w}-6 \mathrm{~m}}$ & 0.38 & 0.22 & 0.13 \\
$\mathrm{GR}_{\mathrm{b}-\mathrm{w}}$ & $\mathrm{GR}_{\mathrm{b}-9 \mathrm{~m}}$ & 0.31 & 0.10 & 0.19 \\
$\mathrm{GR}_{\mathrm{b}-\mathrm{w}}$ & $\mathrm{GR}_{\mathrm{w}-9 \mathrm{~m}}$ & 0.19 & -0.04 & 0.10 \\
$\mathrm{GR}_{\mathrm{b}-\mathrm{w}}$ & $\mathrm{GR}_{6 \mathrm{~m}-9 \mathrm{~m}}$ & 0.52 & 0.30 & -0.03 \\
$\mathrm{GR}_{\mathrm{b}-6 \mathrm{~m}}$ & $\mathrm{GR}_{\mathrm{w}-6 \mathrm{~m}}$ & 0.57 & 0.88 & 0.81 \\
$\mathrm{GR}_{\mathrm{b}-6 \mathrm{~m}}$ & $\mathrm{GR}_{\mathrm{b}-9 \mathrm{~m}}$ & 0.54 & 0.91 & 0.24 \\
$\mathrm{GR}_{\mathrm{b}-6 \mathrm{~m}}$ & $\mathrm{GR}_{\mathrm{w}-9 \mathrm{~m}}$ & 0.67 & 0.77 & 0.37 \\
$\mathrm{GR}_{\mathrm{b}-6 \mathrm{~m}}$ & $\mathrm{GR}_{6 \mathrm{~m}-9 \mathrm{~m}}$ & 0.72 & 0.82 & 0.33 \\
$\mathrm{GR}_{\mathrm{w}-6 \mathrm{~m}}$ & $\mathrm{GR}_{\mathrm{b}-9 \mathrm{~m}}$ & 0.77 & 0.66 & 0.29 \\
$\mathrm{GR}_{\mathrm{w}-6 \mathrm{~m}}$ & $\mathrm{GR}_{\mathrm{w}-9 \mathrm{~m}}$ & 0.42 & -0.26 & 0.10 \\
$\mathrm{GR}_{\mathrm{w}-6 \mathrm{~m}}$ & $\mathrm{GR}_{6 \mathrm{~m}-9 \mathrm{~m}}$ & 0.48 & 0.48 & 0.20 \\
$\mathrm{GR}_{\mathrm{b}-9 \mathrm{~m}}$ & $\mathrm{GR}_{\mathrm{w}-9 \mathrm{~m}}$ & 0.82 & 0.87 & 0.90 \\
$\mathrm{GR}_{\mathrm{b}-9 \mathrm{~m}}$ & $\mathrm{GR}_{6 \mathrm{~m}-9 \mathrm{~m}}$ & 0.37 & 0.78 & 0.71 \\
$\mathrm{GR}_{\mathrm{w}-9 \mathrm{~m}}$ & $\mathrm{GR}_{6 \mathrm{~m}-9 \mathrm{~m}}$ & 0.30 & 0.87 & 0.83 \\
\hline
\end{tabular}

$r_{a}=$ direct additive effect genetic correlation, $r_{m}=$ maternal genetic correlation, $r_{p}=$ phenotypic correlation, GR= growth rate, b, w, 6m, 9m: birth, weaning, at 6 month, at 9 month, respectively. 


\section{REFERENCES}

Abbasi, M.A., Abdollahi-Arpanahi, R. A .Maghsudi, R. Vaez Torshizi and A. Nejati-Javaremi, 2012. Evaluation of models for estimation of genetic parameters and maternal effects for early growth traits of Iranian Baluchi sheep. Small Ruminant Research 104: 62-69

Akaike, H., 1973. Informtion theory and an extension of the maximum likelihood principle in: Petrov BN. Csaki F (eds) proceedings of the 2nd international Symposium Theory Akademiai Kiado, Budapest, Hungary, 267-81

Baneh, H, S.H. Hafezian, A. Rashidi and M. Gholizadeh, 2010. Estimation of genetic parameters of body weight traits in Ghezel sheep. Asian-Aust. J. Anim. Sci. 23: 149-153

Barazandeh, A., S . Molaei Moghbeli, M .Vatankhah and Mohammadabadi, 2011. Estimating nongenetic and genetic parameters of pre-weaning growth traits in Raini Cashmere goat. Trop Anim. Health Prod 44, 864-867

Boldman, K. G. L., A. L. D. Kriese, C. P. Van Vleck and Van Tassell, 1995. A manual for use of TDFREML.A set of programs to obtain estimates of variances and covariances.US. Department of Agriculture, Agriculture Research Service, Washington DC.

Boujenane, I. and J. kansari, 2002. Estimates of (co) variance due to direct and maternal effects for body weights in Timahdite sheep. Anim. Sci., 74:409-414

Bradford, C.E., 1972.The role of maternal effects in animal breeding. VII. Maternal effects in sheep. J. Anim. Sci.35: 1324-1334

Ekiz, B., 2005. Estimates of Maternal Effects for Preand Post-Weaning Daily Gain in Turkish Merino Lambs.Turik j. Vet. Anim. Sci. 29:399-407

Ekiz, B., M. Ozcan and A. Yilmaz, 2004. Estimates of genetic parameters for direct and maternal effects with six different models on birth and weaning weights of Turkish Merino lambs Turk. J. Vet. Anim Sci. 28: 383-389

El-Wakil, Salwa I.and S. M. A. Gad, 2014. Evaluation of direct and maternal (co) variance components and heritabilities for some body weights and growth traits in Barki sheep. Egyptian Journal of Sheep \& Goat Sciences, 9 (1): $21-30$

El-Wakil, Salwa I., ManalElsayed, A. M. Ahmed, R. R. Sadek and A. A. Nigm, 2009. Genetic and phenotypic parameters of birth, weaning and yearling body weights of Barki sheep raised in the north western coast of Egypt.Egyptian J. Anim. Prod., 46 (1): 43-52

Ghafouri-Kesbi F. and M. P. Eskandarinasab, 2008. An evaluation of maternal influences, on growth traits: the Zandi sheep breed of Iran as an example. Journal of Animal and Feed Sciences, 17: 519-529

Ghafouri-Kesbi, F., and H. Baneh, 2012. Genetic parameters for direct and maternal effects on growth traits of sheep.ArchivTierzucht, 55 (6): 603-611

Lewis, R.M. and P.R. Beatson, 1999. Choosing maternal-effect models to estimate (co)variances for live and fleece weight in New Zealand Coopworth sheep. Livest. Prod. Sci. 58: 137-150.

Maniatis, N. and G.E. Pollott, 2002. Maternal effects on weight and ultrasonically measured traits of lambs in a small closed Suffolk flock. Small Rum. Res. 45: 235-246

Maria, G.A., K.G. Boldman and L.D. van Vleck, 1993. Estimates of variances due to direct and maternal effects for growth traits of Romanov sheep. J. Anim. Sci. 71: 845-849

Matika, O., J.B. van Wyk, G.J. Erasmus and R.L. Baker, 2003. Genetic parameter estimates in Sabi sheep. Livest. Prod. Sci. 79:17-28

Meyer, K., 1992.Variance components due to direct and maternal effects for growth traits of Australian beef cattle. Livest. Prod. Sci. 31: 179204

Mousa, E., L.D. van Vleck and K.A. Leymaster, 1999. Genetic parameters for growth traits for a composite terminal sire breed of sheep. J. Anim. Sci. 77: 1659-1665

Pollott, G.E., O. Gursoy and K. Kirk, 1998. The genetics of meat and milk production in Turkish Awassi sheep. In: Proceeding of the 6th world congress on genetic applied to livestock production, Armidale, NSW. Australia, 11-16 January 1998, 24:177-180

SAS, 2004.Statistical Analysis System. SAS Users Guide: Statistics. SAS Institute Inc. Editors, Cary, NC.

Snyman, M.A., G.J . Erasmus, J.B. van Wyk and J.J.Olivier, 1995. Direct and maternal (co)varince components and heritability estimates for body weight at different ages and fleece traits in Afrino sheep. Livest. Prod. Sci. 44: 229-235

Van Wyk, J. B., J. W. Swanepoel, S. W. P. Cloete, J. J. Olivier and G. J. Delport, 2008. Across flock genetic parameters for yearling body weight and fleece traits in the South African Dohne Merino population. S. Afr. J. Anim. Sci. 38: 31-37

Van Wyk, J.B., M.D. Fair and S.W.P.Cloete, 2003. Revised models and genetic parameter estimates for production and reproduction traits in the Elsenburg Dormer sheep stud. S. Afr. J. Anim. Sci. 33: 213-222

Yazdi, M.H., M. G. Engstr, A. Nasholm, K. Johansson, H. Jorjani and L.E. Liljedahl, 1997. Genetic parameters for lamb weight at different ages and wool production in Baluchi sheep. Anim. Sci. 65: 224-255 
الهدف من هذه الدراسة هو البحث عن أهمية التأثيرات المباشرة والأمية علي معدلات النمو المأخوذة على فترات مختلفة من عمر الأغنام

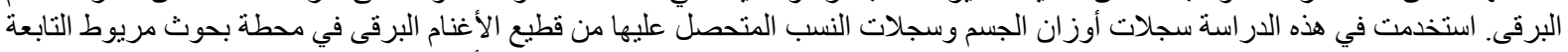

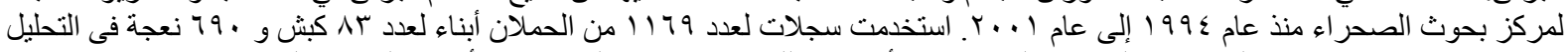

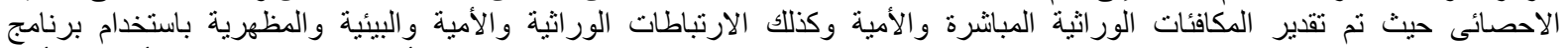

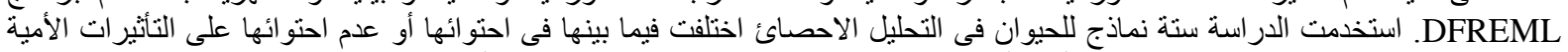

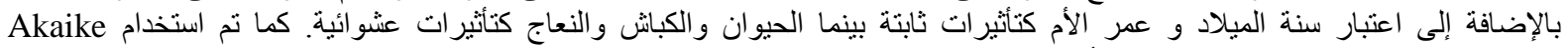
information criterion (AIC)

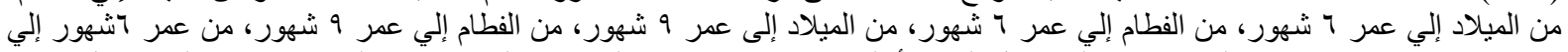

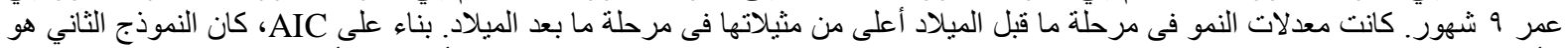

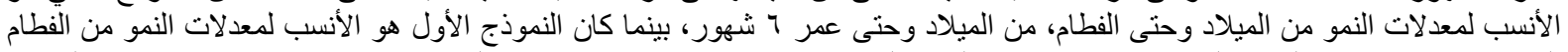

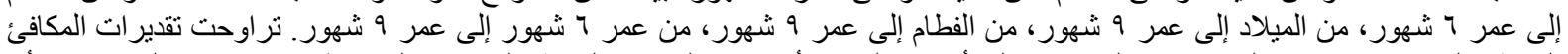

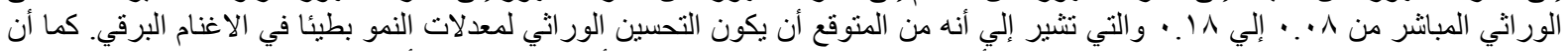

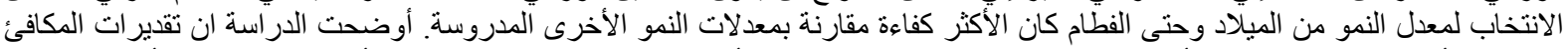

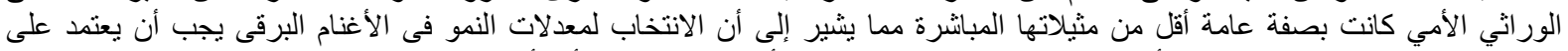

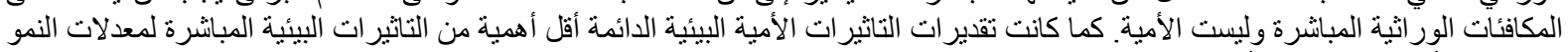

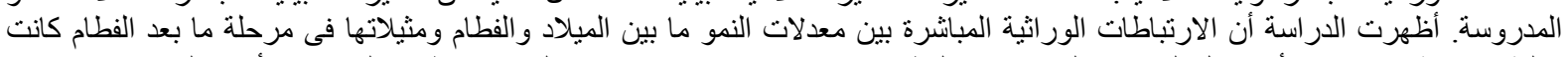
عالية وموجبة مما يوضح أن معدل النمو من الميلاد حتى الفطام قل يكون معيار انتخابي مناسب لتحسين لتحسين مظاهر النمو في الأغنام البرقي. 